\title{
Tuberculosis incidence and risk factors among patients living with HIV/AIDS in public health service institutions in Brasilia, Federal District
}

\author{
Incidência e fatores de risco para tuberculose em pacientes vivendo com \\ HIV/AIDS atendidos nos serviços públicos de saúde \\ em Brasília, Distrito Federal
}

\author{
Leonor Henriette de Lannoy ${ }^{1}$, Juan José Cortez-Escalante ${ }^{2}$, \\ Maria do Socorro Nantua Evangelista ${ }^{3}$ and Gustavo Adolfo Sierra Romero ${ }^{2}$
}

\begin{abstract}
In order to estimate the incidence of and risk factors for developing tuberculosis, the clinical charts of a retrospective cohort of 281 HIV-positive adults, who were notified to the AIDS Program of the Health Department of Brasilia in 1998, were reviewed in 2003. All the patients were treatmentnaive regarding antiretroviral therapy at the time of inclusion in the cohort. Twenty-nine patients were identified as having tuberculosis at the start of the study. Thirteen incident tuberculosis cases were identified during the 60 months of follow-up, with an incidence density rate of 1.24/100 personyears. Tuberculosis incidence was highest among patients with baseline CD4+ T-lymphocyte counts $\leq 200$ cells/ $\mu 1$ who were not using antiretroviral therapy (incidence $=5.47 ; 95 \% \mathrm{CI}=2.73$ to 10.94 ). Multivariate analysis showed that baseline CD4+ T-lymphocyte counts $\leq 200$ cells/pl (adjusted hazard ratio $[\mathrm{AHR}]=5.09 ; 95 \% \mathrm{CI}=1.27$ to $20.37 ; \mathrm{p}=0.02)$ and non-use of antiretroviral therapy $(\mathrm{AHR}=12.17 ; 95 \% \mathrm{CI}=2.6$ to 56.90 ; $\mathrm{p}=0.001$ ) were independently associated with increased risk of tuberculosis.
\end{abstract}

Key-words: Tuberculosis. Incidence. Human immunodeficiency virus. Acquired immunodeficiency syndrome. Risk factors. Survival.

\section{RESUMO}

Para estimar a incidência e os fatores de risco para desenvolver tuberculose foram revisados em 2003 os $\leq$ prontuários de uma coorte retrospectiva de 281 adultos infectados pelo HIV que foram notificados ao Programa de AIDS da Secretaria de Saúde de Brasília em 1998. Todos os pacientes eram virgens de tratamento anti-retroviral no momento da inclusão na coorte. Vinte e nove pacientes foram identificados com tuberculose na avaliação basal. Treze casos incidentes de tuberculose foram identificados durante os 60 meses de seguimento com densidade de incidência de

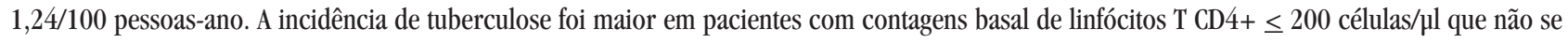
encontravam em uso de terapia anti-retroviral 5,47 (IC95\%=2,73 a 10,94). A análise multivariada demonstrou que a contagem basal de linfócitos T CD $4+\leq 200$ células/ $\mu$ (adjusted hazard ratio $[\mathrm{AHR}]=5,09 ; \mathrm{IC} 95 \%=1,27$ to 20,37; $\mathrm{p}=0,02)$ e 0 não uso de terapia anti-retroviral (AHR=12,17; IC95\% $=2,6$ to 56,$90 ; p=0,001)$ estiveram independentemente associados a um risco maior de tuberculose.

Palavras-chaves: Tuberculose. Incidência. Vírus da imunodeficiência humana. Síndrome da imunodeficiência adquirida. Fatores de risco. Sobrevivência.

The emergence and dissemination of human immunodeficiency virus (HIV) in the 1980s promoted increased tuberculosis (TB) incidence around the world, even though in developed countries it had been considered under control ${ }^{691025}$.

TB is one of the most common causes of morbidity and mortality among HIV patients living in low-income countries ${ }^{10}$. Some estimates have shown that 30 to $60 \%$ of HIV patients are carriers of Mycobacterium tuberculosis with an 8 to $10 \%$ likelihood per year of developing the disease, whereas among immunocompetent individuals, the lifetime risk of $\mathrm{TB}$ reaches $10 \%^{139}$. HIV increases the risk of progression from latent Mycobacterium tuberculosis infection, early infection or reinfection to active disease ${ }^{810}$. Previous studies have demonstrated that patients living with HIV/AIDS have a poor prognosis when

\footnotetext{
1. Unidade Mista de Saúde de Brasília, Secretaria de Estado de Saúde do Distrito Federal, Brasília, DF. 2. Núcleo de Medicina Tropical, Universidade de Brasília, Brasília, DF. 3. Departamento de Enfermagem, Faculdade de Ciências da Saúde, Universidade de Brasília, Brasília, DF.

Financial support: National Council for Scientific and Technological Development (CNPq) of the Ministry of Science and Technology (MCT), Brazil.

Address to: Dr. Juan José Cortez-Escalante, Núcleo de Medicina Tropical/UnB. Campus Universitário Darcy Ribeiro, Caixa Postal 04517, 70904-970 Brasília, DF.

Tel: 5561 3273-5008, Fax: $55613273-2811$

e-mail: jcorteze@unb.br

Recebido para publicação em 02/01/2008

Aceito em 25/09/2008
} 
they have TB that is also associated with low CD4+ T-lymphocyte counts and limited access to highly active antiretroviral therapy $($ HAART) 211203145 .

The introduction of HAART has markedly changed the natural history of HIV infection in both developed and developing countries, with a notable reduction in the risk of contracting opportunistic infections (OI) such as Pneumocystis jirovecii pneumonia, Mycobacterium avium complex infection and cytomegalovirus retinitis ${ }^{35}$. In Brazil, access to HAART has been available since 1996, with the introduction of protease inhibitors and other potent drugs such as non-nucleoside analogues of reverse transcriptase. These drugs have promoted a significant reduction in overall OI, prolonged patient survival and improved quality of life for the patients. In addition, HAART has produced changes in the clinical characteristics ${ }^{28}$ and prognosis among HIV/TB coinfected patients ${ }^{1}$.

In this study, we addressed the issues of incidence, survival and risk of TB disease among HIV-infected patients who were notified to the AIDS Program of the Health Department of Brasilia, Federal District.

\section{PATIENTS AND METHODS}

Retrospective cohort. We identified TB-naive adult patients among all the HIV/AIDS cases notified to the AIDS Program of the Health Department of Brasilia, Federal District, during 1998. The exclusion criteria for our study included lack of clinical records, healthcare at private hospitals and death within the first month after HIV diagnosis.

The patients were followed up for 60 months at any of the seven health centers in Brasilia that were able to care for people living with HIV/AIDS and TB. Enrolment was independent of disease stage and degree of immunodeficiency. Data were collected from clinical records according to standardized criteria on structured forms at registration, and again every six months until December 2003. AIDS was defined according to the 1993 revised classification system for HIV infection of the Centers for Disease Control and Prevention ${ }^{7}$ and the Rio de Janeiro/Caracas criteria ${ }^{37}$. HIV and TB infection were defined in accordance with the Brazilian Ministry of Health guidelines for TB and HIV/AIDS. These guidelines included:

Tuberculosis diagnosis: identification of Mycobacterium tuberculosis in cultures or acid-fast smears in sputum or other tissues, compatible histological findings from tissue biopsies or compatible clinical features ${ }^{13}$. When this last criterion was positive, the TB diagnosis was confirmed by means of a good response to specific anti-TB treatment maintained for at least two months.

The TB-free group was formed by patients without these features in spite of regular clinical and laboratory evaluations as advocated by the Brazilian National Sexually Transmitted Diseases/AIDS Program ${ }^{39}$, as well as absence of any clinical records of TB.

Hunan immunodeficiency virus diagnosis: positive enzyme-linked immunosorbent assay (ELISA) confirmed by either immunofluorescence or the western blot test ${ }^{37}$.
Initial use of HAART was defined when the patient had used antiretroviral drugs for at least three uninterrupted months starting from the cohort inception date.

Patients who did not complete the follow-up period and remained TB-free were censored at the last medical evaluation available before death, as were those who transferred to health units outside of the study area or who were lost from the follow-up.

Tuberculosis incidence and risk estimates. Patients who were diagnosed as having TB between January 1998 and December 2003 were included in the analysis.

Incidence rate: the incidence density of TB was calculated by dividing the number of patients with TB by the person-years of follow-up of all patients at risk. Only the first detected episode of TB was considered for calculating the incidence rate. For a large number of patients, the diagnosis of HIV infection was concomitant with the TB diagnosis. Therefore, the incidence density was calculated for two groups according to the time of TB diagnosis: first, for patients who developed TB after the cohort inception, and second, for all patients including those having both HIV and TB diagnosis at the inception of the cohort. This approach was chosen because it better represented the influence of TB as a serious reason for focusing on persons with unknown HIV infections.

Risk estimates and survival analysis: we estimated the mean TB-free survival time and probability by means of a Kaplan-Meier curve. The incidence density and strength of association were estimated by means of the hazard ratio, using the Cox proportional hazards regression model. The patients were stratified according to their baseline CD4+ T-lymphocyte count $(\leq 200$ and $>200$ cells/ $\mu$ l) and the use of HAART. The Cox proportional hazards regression model was run in relation to sex, age, transmission risk group, CD4+ T-lymphocyte count, viral load and use of HAART, to obtain the adjusted hazard ratio. Patients with simultaneous diagnoses of TB and HIV infection were excluded from the survival and Cox proportional hazards regression analysis.

Characteristics of patients with tuberculosis. The clinical and epidemiological characteristics of patients during their TB episodes were obtained from clinical records. The characteristics recorded included age, sex, CD4+ T-lymphocyte count, HIV viral load, use of HAART and clinical presentation of TB.

Statistical analysis. Stata software (version 8; Stata Corporation, College Station, Texas, USA) was used for calculating the incidence and confidence intervals (95\% CI), assuming a Poisson distribution of events. The survival analysis was performed by means of a Kaplan-Meier life table method to assess the equality of the survival function using the log-rank test, and by means of the Cox proportional hazards regression model. Variables associated with TB development with $p<0.5$ in the crude analysis were included in the multivariate approach in the initial model. Variables were removed from the model if the value of alpha was greater than 0.05 .

\section{RESULTS}

During 1998, 484 naive adult patients were reported as having HIV/AIDS. Of these, 173 were excluded: 85 did not have 
clinical records available, 26 attended private hospitals and 62 died within the first month after HIV diagnosis. Therefore, a total of 281 (58\%) HIV-infected persons were enrolled in the study. Among them, 29 were diagnosed as having simultaneous HIV and TB infection at the cohort inception.

The other 252 patients enrolled in the study were $59 \%$ male. The main HIV transmission routes were: unprotected sex $(56 \%$ heterosexual and $21 \%$ men who had sex with men [MSM]), intravenous drug use (IDU) in 14\% of the patients and unknown cause in $9 \%$ of the patients. At diagnosis, the median age (with P25 - P75) was 31 years (25-37). The median (P25 - P75) baseline for the CD4+ T-lymphocyte count was 196 cells/ $\mu 1$ (59418) and the viral load was $5.1 \log$ RNA copies/ $\mu$ (4.4-5.5).

Tuberculosis incidence. Thirteen patients were diagnosed as having TB during follow-up. All of the HIV-infected patients contributed 1048 person-years of follow-up. Those TB cases yielded an incidence density of 1.24 (95\% CI: 0.66 to 2.12 ) events per 100 person-years of observation (PYO). The incidence density for the 42 coinfected patients after including 29 patients with simultaneous TB and HIV infection at the cohort inception was 4.01 (95\% CI: 3.13 to 5.75) events per 100 PYO.
Among these patients, six showed clinical findings and radiographic images that were compatible with $\mathrm{TB}$, four had positive sputum for acid-fast bacilli (AFB), two had positive cultures for Mycobacterium tuberculosis and one showed compatible histological findings in tissue biopsies.

Survival. Twenty-nine TB patients diagnosed at the inception were excluded from the survival analysis. Two-hundred and fiftytwo patients were thus included. Figure 1 shows the Kaplan-Meier estimates of TB-free survival proportion after diagnosis of HIV infection, in the overall cohort and among patients with CD4+ T-lymphocyte counts categorized as $\leq 200$ and $>200$ cells/ $\mu \mathrm{l}$, as stratified by the use of HAART. Survival was significantly worse ( $p<0.001$ using the log-rank test) among the patients with CD4+ T-lymphocyte counts 200 and among those who were not using HAART. Patients who showed both of these characteristics had the worst mean survival and highest hazard ratio for developing TB (Table 1). The Cox proportional hazards model including sex, baseline CD4+ T-lymphocyte counts, HIV baseline viral load and use of HAART was used to assess and correct for confounding factors. After adjustments were done, CD 4 count $\leq 200$ and non-use of HAART remained the most powerful predictors of poor survival (Table 2).

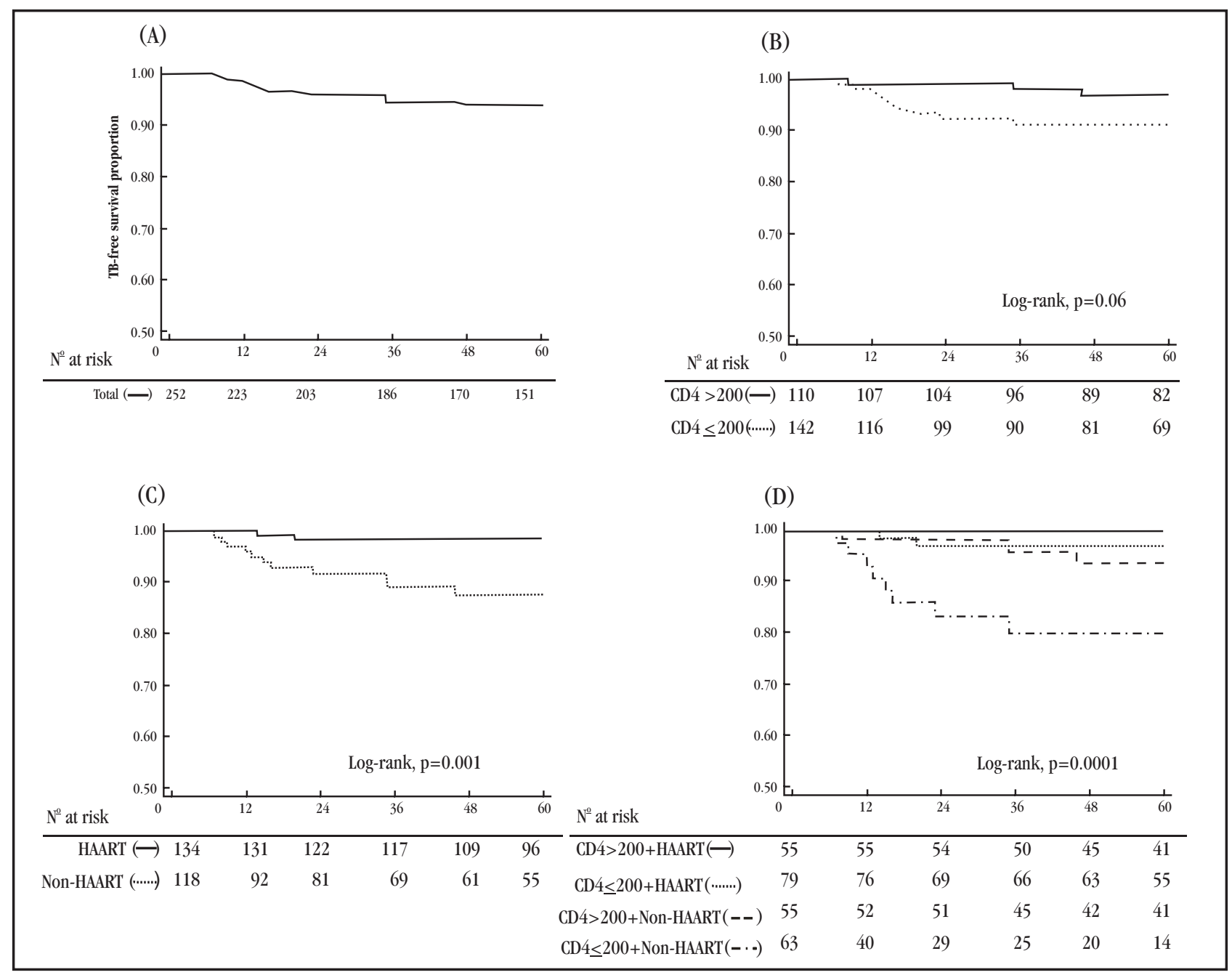

Figure 1 - Kaplan-Meier plots of TB-free survival proportion: (A) in the overall cohort; (B) among patients stratified according to baseline CD4+ Tlymphocyte count; (C) among patients stratified according to use of HAART; (D) among patients stratified according to baseline CD4+ T-lymphocyte count and use of higly active anti-retroviral therapy. 
Table 1 - Effect of baseline CD4+ T-lymphocyte cell counts and higly active anti-retroviral therapy use on the risk of tuberculosis disease among 252 patients living with HIVIAIDS in Brasilia, Federal District.

\begin{tabular}{lccc}
\hline Baseline parameters & $\begin{array}{c}\text { Incidence rate } \\
\text { cases per 100 PYO }(95 \% \mathrm{CI})\end{array}$ & $\begin{array}{c}\text { Hazard ratio } \\
(95 \% \mathrm{CI})\end{array}$ & $\begin{array}{c}\text { Mean survival } \\
\text { months }(95 \% \mathrm{CI})\end{array}$ \\
\hline CD4 $>200+$ HAART & 0 & $1.0^{*}$ & 60.0 \\
CD4 $\leq 200+$ HAART & $0.60(0.15-2.37)$ & $4.5(1.2-16.4)$ & $58.8(57.2-60.4)$ \\
CD4 $>200+$ non-HAART & $1.26(0.41-3.90)$ & $10.1(2.2-45.8)$ & $58.2(55.9-60.4)$ \\
CD4 $\leq 200+$ non-HAART & $5.47(2.73-10.94)$ & $44.9(5.6-361.8)$ & $51.5(46.2-56.8)$
\end{tabular}

PYO: person-years of observations, HAART: highly active antiretroviral therapy, $95 \%$ CI: $95 \%$ confidence interval.

*denominator of hazard ratio.

Table 2 - Hazard ratios for tuberculosis according to the Cox proportional hazards regression model, adjusted for baseline parameters among 252 patients living with HIV/AIDS in Brasilia, Federal District.

\begin{tabular}{|c|c|c|c|c|}
\hline & Crude hazard ratio & & Adjusted hazard ratio & \\
\hline Baseline parameters & $(95 \% \mathrm{CI})$ & $p$ & $(95 \% \mathrm{CI})$ & $p$ \\
\hline Male Sex & $1.64(0.50-5.32)$ & 0.41 & & \\
\hline Age $<30$ years & $0.88(0.30-2.62)$ & 0.82 & & \\
\hline \multicolumn{5}{|l|}{ Transmission risk behavior } \\
\hline intravenous drug use & $0.50(0.07-3.85)$ & 0.51 & & \\
\hline HIV viral load $>5 \log$ & $1.57(0.43-5.72)$ & 0.50 & & \\
\hline T-lymphocyte CD $4 \leq 200$ cells/ $\mu \mathrm{l}$ & $3.22(0.89-11.71)$ & 0.07 & $4.46(1.21-16.35)$ & 0.024 \\
\hline Non-use of antiretroviral treatment & $8.06(1.79-36.38)$ & 0.007 & $10.07(2.21-45.81)$ & 0.003 \\
\hline
\end{tabular}

Clinical and epidemiological characteristics of human immunodeficiency virus-tuberculosis coinfected patients. From 1998 to 2003, 42 patients were diagnosed with TB, and $67 \%$ of them were male. The types of HIV transmission included heterosexual intercourse for $55 \%$ of the subjects, intravenous drug use for $21 \%$, men who had sex with men for $12 \%$, and others for 12\%. The median (P25 - P75) baseline CD4+ T-lymphocyte count was 99 (63-260) cells/ $\mu 1$ and the HIV viral load was 5.4 (5.0-5.5) $\log$ RNA copies/ $\mu 1$. In Table 3, the characteristics of HIV/AIDS patients at the time of TB diagnosis are described.

The TB cases were diagnosed at medians (P25-P75) of 14 (10-21) and 17 (14-20) months after cohort inception among the patients who did and did not use HAART, respectively. In the group of patients with a baseline CD4+ count $>200$ cells/ $\mu \mathrm{l}$, TB cases were diagnosed at a median (P25-P75) of 35 (8-46) months among patients who did not use HAART, and no cases were identified among HAART users.

Table 3 - Characteristics of 42 HIV-TB coinfected patients diagnosed from 1998 to 2003 in Brasilia, Federal District.

\begin{tabular}{|c|c|c|}
\hline & $\begin{array}{c}\text { Detected at cohort } \\
\text { inception } \\
n^{0}=29\end{array}$ & $\begin{array}{l}\text { Detected during } \\
\text { follow-up } \\
\mathrm{n}^{0}=13\end{array}$ \\
\hline Male sex (\%) & 66 & 69 \\
\hline Age (median [P25 - P75] years) & $34(30-42)$ & $35(27-36)$ \\
\hline \multicolumn{3}{|l|}{ Transmission risk behavior to HIV (\%) } \\
\hline unprotected heterosexual contacts & 45 & 77 \\
\hline intravenous drug use & 28 & 8 \\
\hline men who had sex with men & 17 & 0 \\
\hline unknown & 10 & 15 \\
\hline T-lymphocytes CD4+ count (median [P25 - P75] cells/ $\mu \mathrm{l}$ ) & $96(65-339)$ & $64(34-99)$ \\
\hline 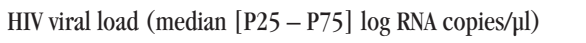 & $5.3(5.0-5.7)$ & $5.0(3.4-5.8)$ \\
\hline Non-use of HAART (\%) & $100^{*}$ & 85 \\
\hline \multicolumn{3}{|l|}{ Clinical presentation of TB (\%) } \\
\hline pulmonary & 52 & 62 \\
\hline extrapulmonary & 21 & 23 \\
\hline pulmonary + extrapulmonary & 27 & 15 \\
\hline \multicolumn{3}{|l|}{ Extrapulmonary TB presentation (\%) } \\
\hline lymph node & 64 & 40 \\
\hline miliary & 14 & 40 \\
\hline others*** & 22 & 20 \\
\hline
\end{tabular}

HIV: human immnunodeficiency virus, RNA: ribonucleic acid, HAART: highly active antiretroviral therapy, TB: tuberculosis,

*These patients did not use antiretroviral treatment, because TB diagnosis was at the same time as HIV diagnosis, ** Pleural, meningeal and genitourinary tuberculosis. 


\section{DISCUSSION}

Analysis of the incidence of HIV-associated TB infection in the HAART era has always been a difficult task. We approached these issues by analyzing retrospective data from newly diagnosed HIV-patients notified to the AIDS Program in 1998. The patients were from Brasilia, Federal District, which is a medium-level TB transmission area ${ }^{26}$ where the annual TB incidence rate in the general population is less than 20 cases per 100,000 inhabitants ${ }^{38}$ Meanwhile, the national Brazilian annual incidence reaches up to 60 cases per 100,000 inhabitants $^{47}$.

We found an overall TB incidence of 1.24 per 100 PYO. Among patients with advanced immunodeficiency (baseline CD $4 \leq 200$ cells/ $\mu \mathrm{l}$ ) who used HAART, the prognosis for not developing TB disease was better after six years of follow-up, with an incidence rate reduced by around fivefold, compared with patients who did not use HAART. We could not determine the time at which HAART use began to diminish the TB incidence rate, but in a previous large population study, the risk of contracting TB continued to decrease for six months after starting to use HAART ${ }^{17}$.

Previous studies have reported that TB incidence among HIV patients varies from one country to another, depending on the country's health policy regarding HAART use and the local TB prevalence rate. In Ethiopia, where the policy on the use of HAART was established in $2002^{21}$ and where TB rates were high, the coinfection incidence reached 3.7 per $100 \mathrm{PYO}^{47}$. However, in India an incidence of 6.9 per 100 PYO was reported ${ }^{44}$. India approved antiretroviral treatment in $2003^{41}$ and implemented it by 2004 , and the country has continued to have high TB incidence for many years ${ }^{47}$. Similar numbers could be expected in India at present. In Europe and North America, the use of HAART was approved nearly a decade ago ${ }^{2432} 35$, which has resulted in low reported rates of $\mathrm{TB}^{947}$. In Italy, the incidence was 0.79 per 100 PYO $^{14}$, a figure similar to that from the EuroSIDA cohort, which estimated $0.80 \mathrm{~TB}$ cases per $100 \mathrm{PYO}^{23}$. The HAART Cohort Collaboration, an international collaborative study, reported $0.47 \mathrm{~TB}$ cases per $100 \mathrm{PYO}^{17}$. Furthermore, the Adult/Adolescent Spectrum of HIV Disease (ASD) project, a North American study, showed $0.50 \mathrm{~TB}$ cases per $100 \mathrm{PYO}^{22}$. Our observations were thus consistent with the reported incidences in developed countries. However, when considering all TB cases diagnosed at the cohort inception, the incidence then became elevated by around fourfold, which may have reflected a better estimate if we consider the exposure risk period for Mycobacterium tuberculosis infection from seroconversion until HIV diagnosis. The number of simultaneous diagnoses of TB/HIV (69\%; 29 out of 42) showed that the patients knew about their HIV status for the first time when they were also diagnosed with $\mathrm{TB}^{18}$.

Observational studies conducted both in low and in high TB incidence countries have shown that the risk of developing TB has decreased by 70 - 90\% for HIV-infected individuals who received HAART, compared with those who were untreated ${ }^{416236}$. Consequently, the incidence of HIV-associated TB has generally decreased in countries where HAART has become the care standard for HIV-infected individuals. Although HAART may reduce the incidence of $\mathrm{TB}$, it may not completely eliminate the risk. Estimates have shown that early use of HAART averted TB. However, if HAART were started when the CD4+ T-lymphocyte count reached 200 cells/ $\mu$ l or lower, the drug regimen would only be able to reduce $25 \%$ of the TB cases (assuming $85 \%$ coverage of the population). If HAART were started with higher CD4+ levels, then the reduction rate for TB cases would be better ${ }^{46}$. Middle-income countries like Brazil that are attempting to manage concomitant epidemics of TB and HIV/AIDS are thus advised to implement broad public strategies with the aims of increasing the coverage and compliance and stimulating the early use of HAART to avert $\mathrm{OI}$ and TB in the course of HIV infection ${ }^{29}$.

Unlike other OIs that occur when CD4+ T-lymphocyte counts drop to $\leq 200$ cells/ $\mu$ l, active TB occurs through a broader spectrum of immunodeficiency ${ }^{19} 33$. The relative proportions of clinical forms of TB in HIV patients with almost intact immune function are similar to those observed in non-HIV infected patients, i.e. 80 to $85 \%$ presenting pulmonary forms ${ }^{42}$. Among patients with advanced HIV disease, pulmonary tuberculosis has decreased to 50 to $60 \%$, and the likelihood of extrapulmonary involvement rises as the immunity worsens, thus showing a predominance of lymphadenopathy ${ }^{15}$. Most of our patients presented an increased number of extrapulmonary TB forms, with nearly half showing lymph node involvement. These were compatible numbers considering their advanced immunodeficiency.

Nowadays, TB diagnosis among HIV patients follows specific guidelines ${ }^{18}$. However, in some patients, doubt persists about clinical TB diagnoses in spite of using appropriate means of evaluation ${ }^{3}$. In the present study, patients with no microbiological confirmation were assumed to have had TB if the suspected clinical condition had improved after two months of anti-tuberculosis therapy. This has been possible up to now because Brazil has been considered to be a country with low multidrug-resistance TB prevalence ${ }^{47}$. Until now, there has not been an established period for confirming the TB diagnosis from good responses to anti-TB treatment. Reports on patients with difficult TB diagnoses have suggested that this period could vary from 3 weeks ${ }^{30}$ to 3 months ${ }^{5}$.

TB was diagnosed earlier in HIV patients with $\mathrm{CD} 4+\mathrm{T}$ lymphocyte counts of $\leq 200$ cells $/ \mu$ than in patients with higher CD4+ T-lymphocyte counts. Among patients with good adherence to antiretroviral treatment, the first TB cases appeared more than one year after the cohort inception. Sometimes, the immune reconstitution syndrome (IRIS) increases the number of TB cases within the first month after starting HAART use, among HIV patients with severe immunodeficiency ${ }^{17}$, thereby confounding the effectiveness of antiviral treatment for preventing TB. However, we did not have any patients diagnosed with TB because of IRIS after using HAART, since the majority of TB associated with IRIS developed within the first two months of HAART use (usually within the first 2-3 weeks ${ }^{12}$ ).

We have shown in this study that baseline CD4+ T-lymphocyte counts of $\leq 200$ cells/ $\mu$ land lack of HAART use were both independently associated with increased risk of TB, based on the results from our multivariate analysis. Other risk factors have been reported in other countries. In an adult AIDS cohort 
in Cape Town, for individuals aged 33 years or younger, CD4+ Tlymphocyte counts $<100$ cells/ $\mu 1$ and WHO clinical stages 3 and 4 when HAART was first started were identified as risk factors ${ }^{27}$. In a study cohort in the United States, IDU, heterosexual contact, CD4+ T-lymphocyte counts $<100$ cells/ $\mu$ l and lack of any antiretroviral therapy were important risk factors ${ }^{22}$. In Côte d'Ivoire, where TB incidence has been high since the 1990's, a history of TB was an important risk factor for developing HIV-associated $\mathrm{TB}^{40}{ }^{47}$. In Rio de Janeiro, positive PPD (intradermal injection of tuberculin antigen) was identified as an important risk factor among advanced immunodeficiency HIV patients ${ }^{36}$. In our study, the intermediate TB rates in our city and the methodological limitations of our study may have lowered the sensitivity for detecting other risk factors.

One important limitation was the large number of patients seeking medical attention after their first clinical symptoms of advanced immunodeficiency had occurred. This may have caused selection of the patients who were most vulnerable towards developing TB or other OIs in our study. It also yielded a limited estimation of the survival rates when the cohort study began at HIV diagnosis rather than at HIV serological conversion. This resulted in a much higher survival rate among patients with less immunodeficiency, thereby increasing the risk of latent TB progression to active disease. The absence of microbiological confirmation in some patients with TB could be another important limitation. Nonetheless, we could not exclude these cases, because of the known difficulties in confirming TB in HIV/AIDS patients, especially if they are in advanced stages of immunodeficiency. The deaths of some patients from causes other than TB, and patients relocating to another city were also relevant factors to consider. However, we believe that the impact of these factors would have been small because there were many critical patients still at risk by the end of the study period.

In conclusion, our analysis showed that HAART attenuated the increase in TB incidence among HIV patients, especially among severely immunodeficient HIV-infected individuals. Hence, the use of HAART diminished TB risk. Nonetheless, cases of TB appeared several months later in this city, which has low incidence of TB infection. Future prospective adult cohorts need to be established, with the purpose of exploring other risk factors such as social and economic status and TB contact in inpatient or outpatient clinical settings, in order to evaluate their impact on the development of TB among HIV patients.

\section{ACKNOWLEDGEMENTS}

This research was funded by the National Council for Scientific and Technological Development (CNPq) of the Ministry of Science and Technology (MCT), Brazil.

\section{REFERENCES}

1. Aaron L, Saadoun D, Calatroni I, Launay O, Memain N, Vincent V, Marchal G, Dupont B, Bouchaud O, Valeyre D, Lortholary O. Tuberculosis in HIV-infected patients: a comprehensive review. Clinical microbiology and infection 10:388-398, 2004.
2. Aerts D, Jobim R. The epidemiological profile of tuberculosis in southern Brazil in times of AIDS. The International Journal of Tuberculosis and Lung Disease 8:785-791, 2004

3. Anglaret X, Saba J, Perronne C, Lacassin F, Longuet P, Leport C, Vilde JL. Empiric antituberculosis treatment: benefits for earlier diagnosis and treatment of tuberculosis. Tubercle and Lung Disease 75:334-340, 1994.

4. Badri M, Wilson D, Wood R. Effect of highly active antiretroviral therapy on incidence of tuberculosis in South Africa: a cohort study. The Lancet 359:20592064, 2002.

5. Bolukbas C, Bolukbas FF, Kendir T, Dalay RA, Akbayir N, Sokmen MH, Ince AT, Guran M, Ceylan E, Kilic G, Ovunc 0. Clinical presentation of abdominal tuberculosis in HIV seronegative adults. BMC Gastroenterol 5:21, 2005.

6. Brewer TF, Heymann SJ. Long time due: reducing tuberculosis mortality in the 21st century. Archives of Medical Research 36:617-621, 2005.

7. Centers for Disease Control and Prevention (CDC). 1993 revised classification system for HIV infection and expanded surveillance case definition for AIDS among adolescents and adults. Morbidity and Mortality Weekly Report Recommendations and Reports 41:1-19, 1992.

8. Centers for Disease Control and Prevention (CDC). Targeted tuberculin testing and treatment of latent tuberculosis infection. American Thoracic Society. Morbidity and Mortality Weekly Report Recommendations and Reports 49:1-51, 2000 .

9. Centers for Disease Control and Prevention (CDC). Reported Tuberculosis in the United States, 2004. U.S. Department of Health and Human Services; Atlanta, 2005.

10. Corbett EL, Watt CJ, Walker N, Maher D, Williams BG, Raviglione MC, Dye C. The growing burden of tuberculosis: global trends and interactions with the HIV epidemic. Archives of internal medicine 163:1009-1021, 2003.

11. Dheda K, Lampe FC, Johnson MA, Lipman MC. Outcome of HIV-associated tuberculosis in the era of highly active antiretroviral therapy. The Journal of Infectious Diseases 190:1670-1676, 2004.

12. French MA, Price P, Stone SF. Immune restoration disease after antiretroviral therapy. Aids 18:1615-1627, 2004.

13. Fundação Nacional de Saúde. Tuberculose: Guia de vigilância epidemiológica. Ministério da Saúde, Brasília, 2002.

14. Girardi E, Antonucci G, Vanacore P, Libanore M, Errante I, Matteelli A, Ippolito G. Impact of combination antiretroviral therapy on the risk of tuberculosis among persons with HIV infection. Aids 14:1985-1991, 2000.

15. Girardi E, Antonucci G, Vanacore P, Palmieri F, Matteelli A, Lemoli E, Carradori S, Salassa B, Pasticci MB, Raviglione MC, Ippolito G. Tuberculosis in HIV-infected persons in the context of wide availability of highly active antiretroviral therapy. The European Respiratory Journal 24:11-17, 2004.

16. Girardi E, Raviglione MC, Antonucci G, Godfrey-Faussett P, Ippolito G. Impact of the HIV epidemic on the spread of other diseases: the case of tuberculosis. Aids 14 Suppl 3:\$47-S56, 2000.

17. Girardi E, Sabin CA, d'Arminio Monforte A, Hogg B, Phillips AN, Gill MJ, Dabis F, Reiss P, Kirk 0, Bernasconi E, Grabar S, Justice A, Staszewski S, Fatkenheuer G, Sterne JA. Incidence of Tuberculosis among HIV-infected patients receiving highly active antiretroviral therapy in Europe and North America. Clinical Infectious Diseases 41:1772-1782, 2005.

18. Harries A, Maher D, Graham S. TB/HIV: a clinical manual. World Health Organization, Geneva, 2004.

19. Havlir DV, Barnes PF. Tuberculosis in patients with human immunodeficiency virus infection. The New England Journal of Medicine 340:367-373, 1999

20. Hung CC, Chen MY, Hsiao CF, Hsieh SM, Sheng WH, Chang SC. Improved outcomes of HIV-1-infected adults with tuberculosis in the era of highly active antiretroviral therapy. Aids 17:2615-2622, 2003.

21. Jerene DD, Naess AP, Lindtjorn BP. Antiretroviral therapy at a district hospital in Ethiopia prevents death and tuberculosis in a cohort of HIV patients. AIDS Research and Therapy 3:10, 2006.

22. Jones JL, Hanson DL, Dworkin MS, DeCock KM. HIV-associated tuberculosis in the era of highly active antiretroviral therapy. The Adult/Adolescent Spectrum of HIV Disease Group. The International Journal of Tuberculosis and Lung Disease 4:1026-1031, 2000. 
23. Kirk O, Gatell JM, Mocroft A, Pedersen C, Proenca R, Brettle RP, Barton SE, Sudre P, Phillips AN. Infections with Mycobacterium tuberculosis and Mycobacterium avium among HIV-infected patients after the introduction of highly active antiretroviral therapy. EuroSIDA Study Group JD. American Journal of Respiratory and Critical Care Medicine 162:865-872, 2000.

24. Kirk 0, Mocroft A, Katzenstein TL, Lazzarin A, Antunes F, Francioli P, Brettle RP, Parkin JM, Gonzales-Lahoz J, Lundgren JD. Changes in use of antiretroviral therapy in regions of Europe over time. EuroSIDA Study Group. Aids 12:2031-2039, 1998

25. Kirschner D. Dynamics of co-infection with M. Tuberculosis and HIV-1. Theoretical Population Biology 55:94-109, 1999.

26. Kusano MS, Mendes IJ, Alves E, Assis MC. The annual risk of tuberculosis infection in the Federal District (Brazil). Revista Brasileira de Epidemiologia 8:262-271, 2005.

27. Lawn SD, Badri M, Wood R. Tuberculosis among HIV-infected patients receiving HAART: long term incidence and risk factors in a South African cohort. Aids 19:2109-2116, 2005.

28. Lawn SD, Bekker LG, Wood R. How effectively does HAART restore immune responses to Mycobacterium tuberculosis? Implications for tuberculosis control. Aids 19:1113-1124, 2005.

29. Levi GC, Vitoria MA. Fighting against AIDS: the Brazilian experience. Aids 16:2373-2383, 2002.

30. Lewis DK, Peters RP, Schijffelen MJ, Joaki GR, Walsh AL, Kublin JG, Kumwenda J, Kampondeni S, Molyneux ME, Zijlstra EE. Clinical indicators of mycobacteraemia in adults admitted to hospital in Blantyre, Malawi. The International Journal of Tuberculosis and Lung Disease 6:1067-1074, 2002.

31. Manas E, Pulido F, Pena JM, Rubio R, Gonzalez-Garcia J, Costa R, Perez-Rodriguez E, Del Palacio A. Impact of tuberculosis on the course of HIV-infected patients with a high initial CD4 lymphocyte count. The International Journal of Tuberculosis and Lung Disease 8:451-457, 2004.

32. Mocroft A, Vella S, Benfield TL, Chiesi A, Miller V, Gargalianos P, d'Arminio Monforte A, Yust I, Bruun JN, Phillips AN, Lundgren JD. Changing patterns of mortality across Europe in patients infected with HIV-1. EuroSIDA Study Group. The Lancet 352:1725-1730, 1998.

33. Mocroft A, Youle M, Phillips AN, Halai R, Easterbrook P, Johnson MA, Gazzard B. The incidence of AIDS-defining illnesses in 4883 patients with human immunodeficiency virus infection. Archives of internal medicine 158:491-497, 1998

34. Onyebujoh P, Rook GA. Tuberculosis. Nature Reviews Microbiology 2:930-932, 2004
35. Palella Jr FJ, Delaney KM, Moorman AC, Loveless MO, Fuhrer J, Satten GA, Aschman DJ, Holmberg SD. Declining morbidity and mortality among patients with advanced human immunodeficiency virus infection. HIV Outpatient Study Investigators. The New England Journal of Medicine 338:853-860, 1998.

36. Santoro-Lopes G, Pinho AM, Harrison LH, Schechter M. Reduced risk of tuberculosis among Brazilian patients with advanced human immunodeficiency virus infection treated with highly active antiretroviral therapy. Clinical Infectious Diseases 34:543-546, 2002.

37. Secretaria de Vigilância em Saúde. Critérios de definição de casos de aids em adultos e crianças. Programa Nacional de DST e Aids. Ministério da Saúde, Brasília, 2004.

38. Sistema Nacional de Vigilância em Saúde. Relatório de situação: Distrito Federal. Ministério da Saúde, Brasília, 2005

39. Secretaria de Vigilância em Saúde. Recomendações para terapia anti-retroviral em adultos e adolescentes infectados pelo HIV - 2007/2008. Programa Nacional de DST e Aids. Ministério da Saúde, Brasília, 2007.

40. Seyler C, Toure S, Messou E, Bonard D, Gabillard D, Anglaret X. Risk factors for active tuberculosis after antiretroviral treatment initiation in Abidjan. American Journal of Respiratory and Critical Care Medicine 172:123-127, 2005.

41. Sharma DC. India unprepared for antiretroviral treatment plan. The Lancet 362:1988, 2003

42. Sharma SK, Mohan A. Extrapulmonary tuberculosis. The Indian Journal of Medical Research 120:316-353, 2004

43. Song AT, Schout D, Novaes HM, Goldbaum M. Clinical and epidemiological features of AIDS/tuberculosis comorbidity. Revista do Hospital das Clínicas da Faculdade de Medicina da Universidade de São Paulo 58:207-214, 2003.

44. Swaminathan S, Ramachandran R, Baskaran G, Paramasivan CN, Ramanathan U, Venkatesan P, Prabhakar R, Datta M. Risk of development of tuberculosis in HIV-infected patients. The International Journal of Tuberculosis and Lung Disease 4:839-844, 2000 .

45. Van der Sande MA, Schim van der Loeff MF, Bennett RC, Dowling M, Aveika AA, Togun TO, Sabally S, Jeffries D, Adegbola RA, Sarge-Njie R, Jaye A, Corrah T, McConkey S, Whittle HC. Incidence of tuberculosis and survival after its diagnosis in patients infected with HIV-1 and HIV-2. Aids 18:1933-1941, 2004.

46. Williams BG, Dye C. Antiretroviral drugs for tuberculosis control in the era of HIV/AIDS. Science 301:1535-1537, 2003.

47. World Health Organization. Global tuberculosis control: surveillance, planning, financing: WHO report 2006. World Health Organization, Geneva, 2006. 